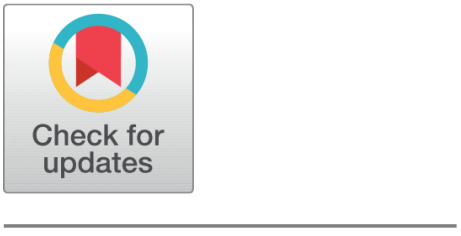

open ACCESS

Received: 07.11.2020

Accepted: 14.12 .2020

Published: 28.12 .2020

Citation: Ramachandruni UR, Namala Y (2020) Analytical solutions of some mechanics problems by Elzaki transform. Indian Journal of Science and Technology 13(47): 4606-4618. https://doi.org/ 10.17485/IJST/v13i47.1971

* Corresponding author.

Tel: +91-9440033373

umrao76@gmail.com

Funding: None

Competing Interests: None

Copyright: (c) 2020 Ramachandruni \& Namala. This is an open access article distributed under the terms of the Creative Commons Attribution License, which permits unrestricted use, distribution, and reproduction in any medium, provided the original author and source are credited.

Published By Indian Society for Education and Environment (iSee)

ISSN

Print: 0974-6846

Electronic: 0974-5645

\section{Analytical solutions of some mechanics problems by Elzaki transform}

\author{
Umamaheshwar Rao Ramachandruni ${ }^{1 *}$, Yuvaraju Namala ${ }^{1}$ \\ 1 Division of Mathematics, Department of Science and Humanities, Sreenidhi Institute \\ of Science of and Technology, Ghatkesar, Medchal, 501301, Telangana, India. Tel.: +91- \\ 9440033373
}

\section{Abstract}

Objectives: To discuss the applicability of new kind of transform technique named as Elzaki transform in solving the higher order ordinary linear differential equations occurred in various categories of vibrations in the field of engineering mechanics. Methods: We have selected some problems in the field of engineering mechanics to study the solutions with the help of Elzaki transform technique. We have used Elzaki transform method and also MATLAB to draw graphs for the obtained solutions of selected problems. Findings: We have successfully applied this new transform technique in finding the analytical solutions and compared with the graphs drawn with MATLAB. Novelty/Applications: We may apply this new kind of transform technique named as Elzaki transform to get the analytical solutions of differential equations.

Keywords: Elzaki transform; differential equations; vibrations

\section{Introduction}

The differential equations have played a central role in every aspect of applied mathematics for long time and also the linear differential equations with constant coefficients find their important applications in the study of mechanical systems ${ }^{(1-3)}$.

Elzaki transform technique is particularly useful for finding solutions of mechanical problems and this technique is very effective for the solution of the response of a linear ordinary differential equation to the given initial data. The Elzaki transform may be used to solve intricate problems in engineering, mathematics and applied science without resorting to a new frequency domain ${ }^{(4-6)}$.

\subsection{Definition of Elzaki transform}

The Elzaki transform is defined for function of exponential order, we consider function on the set A defined by $A=\left\{f(t): \exists M, k_{1}, k_{2}>0,|f(t)|<M e^{\frac{|t|}{k_{j}}}\right.$, if $\left.t \in(-1)^{j} \times(0, \infty)\right\}$, where the constant $\mathrm{M}$ must be a finite number, $k_{1}, k_{2}$ may be finite or infinite. The Elzaki transform of the function $\mathrm{f}(\mathrm{t})$ is defined as $E\{f(t)\}=T(v)=v \int_{0}^{\infty} f(t) e^{\frac{-t}{v}} d t$, $t>0, v \in\left(-k_{1}, k_{2}\right) \cdot{ }^{(1-6)}$ 
Table 1. Elzaki transform of some standard functions ${ }^{(1,2)}$

\begin{tabular}{ll}
\hline$f(t)$ & $E(f(t)]=T(v)$ \\
\hline 1 & $v^{2}$ \\
$\mathrm{t}$ & $v^{3}$ \\
$t^{n}, n \in N$ & $n ! v^{n+2}$ \\
$t^{n}, n>0$ & $\tau(n+1) v^{n+2}$ \\
$e^{a t}$ & $\frac{v^{2}}{1-a v}$ \\
$t e^{a t}$ & $\frac{v^{3}}{(1-a v)^{2}}$ \\
$\frac{t^{n-1} e^{a t}, n=1,2 \ldots}{(n-1) !}$ & $\frac{v^{n+1}}{(1-a v)^{n}}$ \\
Sinat & $\frac{a v^{3}}{1+a^{2} v^{2}}$ \\
Cosat & $\frac{v^{2}}{1+a^{2} v^{2}}$ \\
Sinhat & $\frac{a v^{2}}{1-a^{2} v^{2}}$ \\
Coshat & $\frac{v^{2}}{1-a^{2} v^{2}}$ \\
\hline
\end{tabular}

\subsection{Elzaki Transform of derivatives of function $f(t):$ If $E[f(t)]=T(v)$ then we have}

1. $E\left[f^{\prime}(t)\right]=\frac{1}{v} E\{f(t)\}-v f(0)$

2. $E\left(f^{\prime \prime}(t)\right\}=\frac{1}{v^{2}} E(f(t)\}-f(0)-v f^{\prime}(0)$

3. $E\left\{f^{(n)}(t)\right\}=\frac{1}{v^{n}} E\{f(t)\}-\sum_{k=0}^{n-1} v^{2-n+k} f^{(k)}(0), n=1,2,3 \ldots \ldots{ }^{(2,3)}$

\subsection{Ordinary linear differential equation with constant coefficients:}

The general form of $\mathrm{n}^{\text {th }}$ order linear differential equation with constant coefficients is $\frac{d^{n} y}{d t^{n}}+C_{1} \frac{d^{n-1} y}{d t^{n-1}}+C_{2} \frac{d^{n-2} y}{d t^{n-2}}+\cdots+C_{n-1} \frac{d y}{d t}+$ $C_{n} y=Q(t)$ where $C_{1}, C_{2} \ldots C_{n}$ real constants are and $Q(t)$ is a function of the independent variable $t^{(2,3)}$.

\section{Elzaki transform to an ordinary differential equation}

The Elzaki transform may be used to solve ordinary linear differential equations with initial or boundary conditions. Let $y(0)=a_{0}, y^{\prime}(0)=a_{1}, y^{\prime \prime}(0)=a_{2}, \ldots \ldots, y^{(n-1)}(0)=a_{n-1}$ be the given initial or boundary conditions $\mathrm{n}^{\text {th }}$ ordinary differential equation, where $a_{0}, a_{1}, a_{2}, \ldots \ldots, a_{n-1}$ are the constants. On taking the Elzaki transform on both sides of differential equation and also using these conditions, we obtain an algebraic equation known as subsidiary equation. The solution is the obtained by applying the inverse Elzaki transform ${ }^{(2,3)}$.

\subsection{Solve the differential equation $\frac{d^{2} y}{d t^{2}}+3 \frac{d y}{d t}+2 y=0, y(0)=0, y^{\prime}(0)=1$}

Solution : The given equation can be written as $y^{\prime \prime}(t)+3 y^{\prime}(t)+2 y(t)=0$

Taking the Elzaki transform, we get $E\left\{y^{\prime \prime}(t)\right\}+3 E\left\{y^{\prime}(t)\right\}+2 E\{y(t)\}=0$ 
Using the derivatives of Elzaki transform, gives

$$
\frac{1}{v^{2}} E\{y(t)\}-y(0)-v y^{\prime}(0)+3\left[\frac{1}{v} E\{y(t)\}-v y(0)\right]+2 E\{y(t)\}=0
$$

Substituting the values of the conditions, $y(0)=0, y^{\prime}(0)=1$ in the above equation,

$$
\left[\frac{1}{v^{2}}+\frac{3}{v}+2\right] E\{y(t)\}-0-v \cdot 1-0=0 \Rightarrow\left(\frac{1+3 v+2 v^{2}}{v^{2}}\right) E\{y(t)\}=v
$$

This can be written as $E\{y(t)\}=\frac{v^{3}}{1+3 v+2 v^{2}}=\frac{v^{3}}{(1+2 v)(1+v)}=\frac{v^{2}}{1+v}-\frac{v^{2}}{1+2 v}$

Now taking by applying inverse Elzaki transform on either side, we get

$$
y(t)=E^{-1}\left\{\frac{v^{2}}{1+v}\right\}-E^{-1}\left\{\frac{v^{2}}{1+2 v}\right\}
$$

After further simplification which gives $y(t)=e^{-t}-e^{-2 t}$ as a solution.

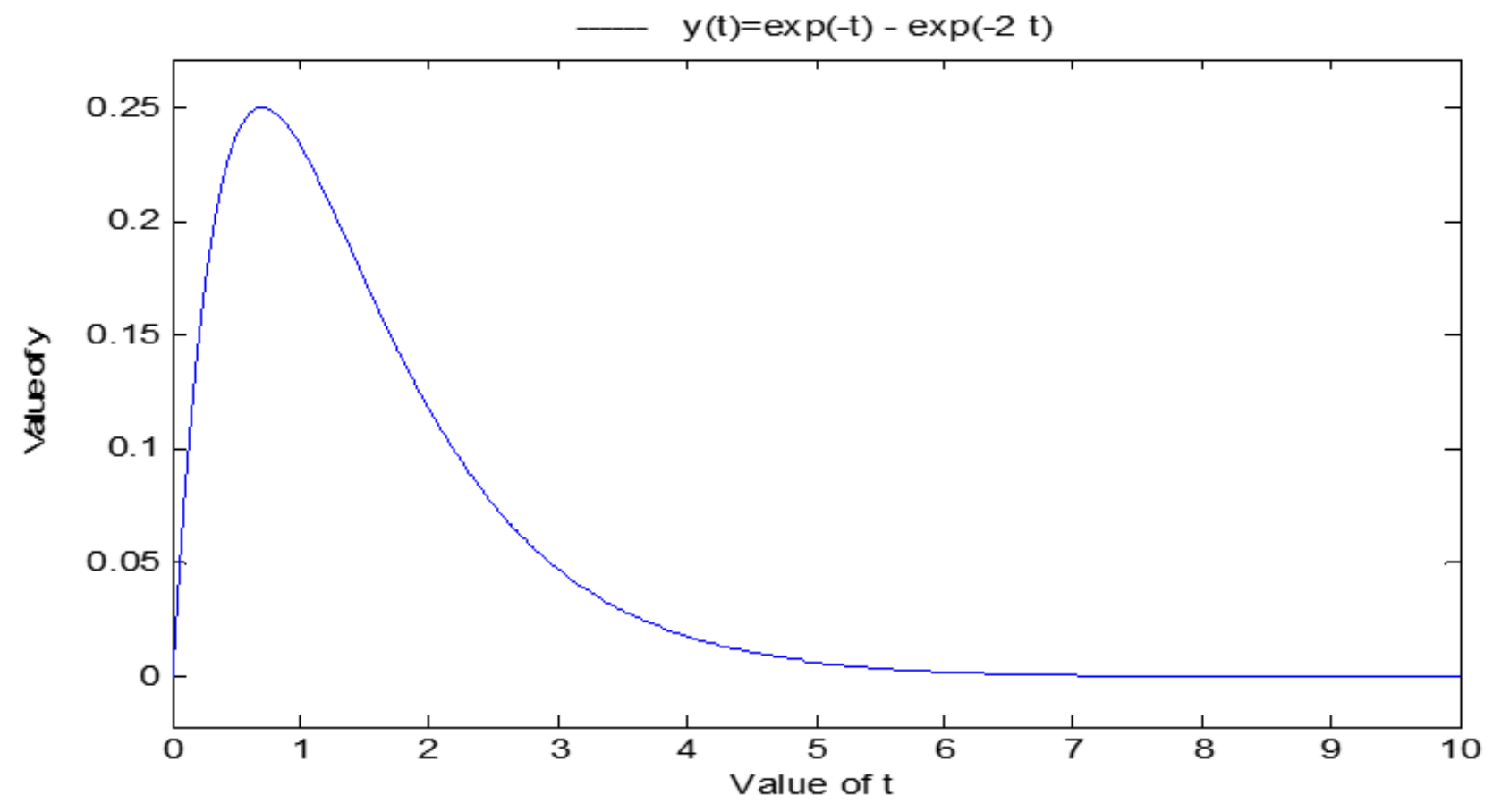

Fig 1.

\subsection{Solve the differential equation $y^{\prime \prime}+y^{\prime}=t^{2}+2 t, y(t)=4, y^{\prime}(t)=-2$ at $t=0$}

Solution : Let $y^{\prime \prime}(t)+y^{\prime}(t)=t^{2}+2 t, y(0)=4, y^{\prime}(0)=-2$

Now taking the Elzaki transform to (2.2.1), we have

$$
\begin{gathered}
E\left\{y^{\prime \prime}(t)\right\}+E\left\{y^{\prime}(t)\right\}=E\left\{t^{2}\right\}+2 E\{t\} \\
\Rightarrow \frac{1}{v^{2}} E\{y(t)\}-y(0)-v y^{\prime}(0)+\left[\frac{1}{v} E\{y(t)\}-v y(0)\right]=2 v^{4}+2 v^{3}
\end{gathered}
$$

Now substituting the values given in the above, we have

$$
\begin{aligned}
& \left(\frac{1}{v^{2}}+\frac{1}{v}\right) E\{y(t)\}-4-v \cdot(-2)-v \cdot 4=2 v^{4}+2 v^{3} \\
\Rightarrow & \left(\frac{1}{v^{2}}+\frac{1}{v}\right) E\{y(t)\}=2 v^{4}+2 v^{3}+2 v+4 \\
\Rightarrow & \left(\frac{1+v}{v^{2}}\right) E\{y(t)\}=2 v^{4}+2 v^{3}+2 v+4
\end{aligned}
$$


Further it can be written as

$$
\begin{aligned}
& E\{y(t)\}=\frac{2 v^{6}+2 v^{5}+2 v^{3}+4 v^{2}}{1+v} \\
& =\frac{2 v^{5}(v+1)+2 v^{2}(v+2)}{1+v} \\
& =2 v^{5}+2 v^{2}+\frac{2 v^{2}}{1+v}
\end{aligned}
$$

Now taking inverse Elzaki transform on both sides of (2.2.2), we get

$$
\begin{aligned}
y(t) & =2 E^{-1}\left\{v^{5}\right\}+2 E^{-1}\left\{v^{2}\right\}+2 E^{-1}\left\{\frac{v^{2}}{1+v}\right\} \\
& =2 \frac{t^{3}}{3 !}+2(1)+2 e^{-t}
\end{aligned}
$$

Therefore $y(t)=\frac{t^{3}}{3}+2+2 e^{-t}$ is the solution.

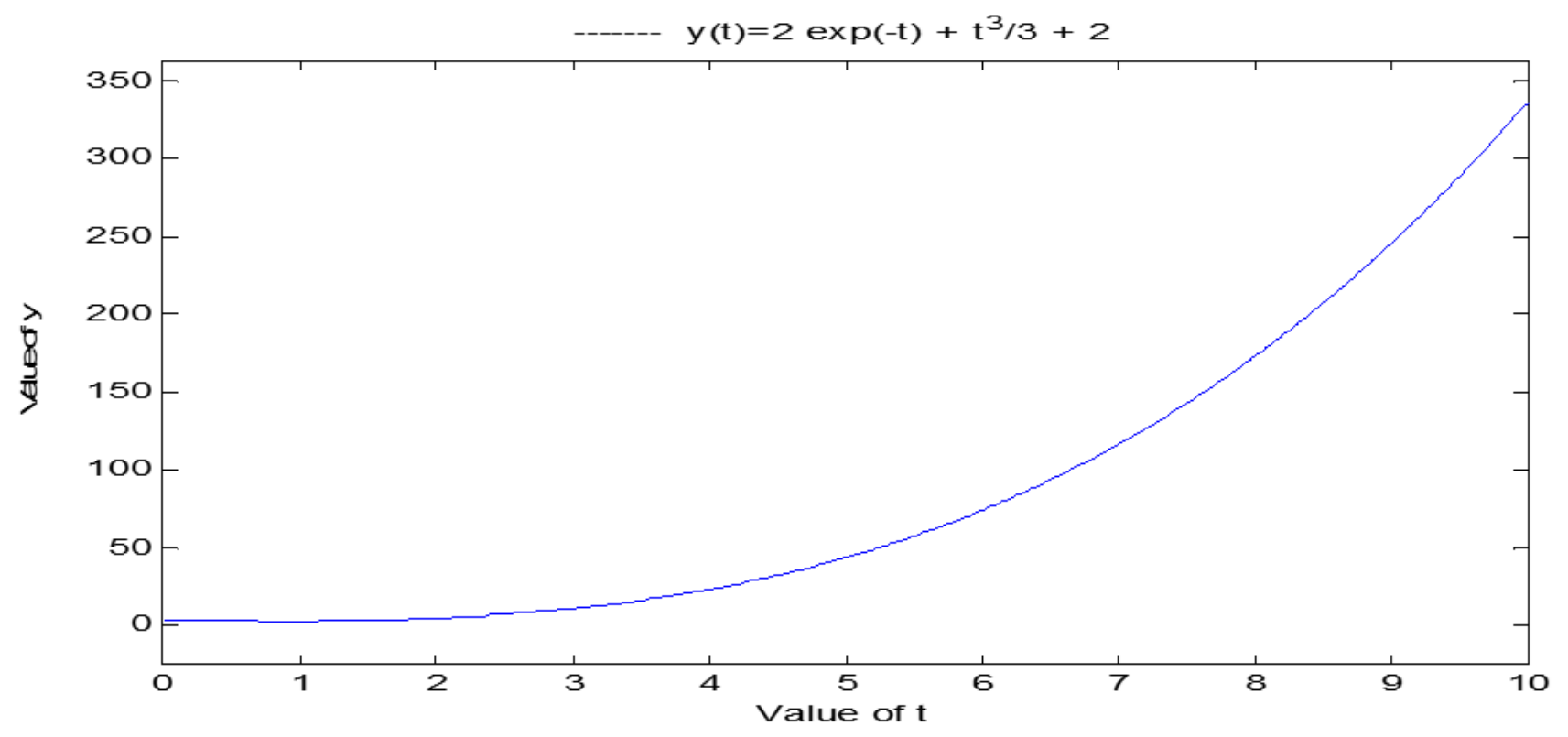

Fig 2.

2.3 Solve $\left(D^{4}-1\right) y=1, y=D y=D^{2} y=D^{3} y=0$, at $t=0$, where $D=\frac{d}{d t}$, is the differential operator

Solution: The given equation can be written as

$$
y^{\prime \prime \prime \prime}-y=1, y(0)=y^{\prime}(0)=y^{\prime \prime}(0)=y^{\prime \prime \prime}(0)=0
$$

Now Taking the Elzaki transform to (2.3.1), we have $E\left\{y^{\prime \prime \prime}(t)\right\}-E\{y(t)\}=E\{1\}$

Using the derivatives of Elzaki transform, we get

$$
\frac{1}{v^{4}} E\{y(t)\}-\frac{1}{v^{2}} y(0)-\frac{1}{v} y^{\prime}(0)-y^{\prime \prime}(0)-v y^{\prime \prime \prime}(0)-E\{y(t)\}=v^{2}
$$

Now substituting the values in conditions at $\mathrm{t}=0$, then

$$
\left(\frac{1}{v^{4}}-1\right) E\{y(t)\}-0-0-0-0=v^{2}
$$


After further simplification, it can be written as

$$
\begin{aligned}
E\{y(t)\} & =\frac{v^{6}}{1-v^{4}} \\
& =-v^{2}+\frac{v^{2}}{1-v^{4}} \\
& =-v^{2}+\frac{v^{2}}{\left(1-v^{2}\right)\left(1+v^{2}\right)} \\
& =-v^{2}+\frac{1}{2}\left(\frac{v^{2}}{1-v^{2}}\right)+\frac{1}{2}\left(\frac{v^{2}}{1+v^{2}}\right)
\end{aligned}
$$

Now by taking inverse Elzaki transform of both sides of (2.3.2), we get

$$
y(t)=-E^{-1}\left\{v^{2}\right\}+\frac{1}{2} E^{-1}\left\{\frac{v^{2}}{1-v^{2}}\right\}+\frac{1}{2} E^{-1}\left\{\frac{v^{2}}{1+v^{2}}\right\}
$$

Therefore, $y(t)=-1+\frac{1}{2} \cosh t+\frac{1}{2} \cos t \quad$ is the solution.

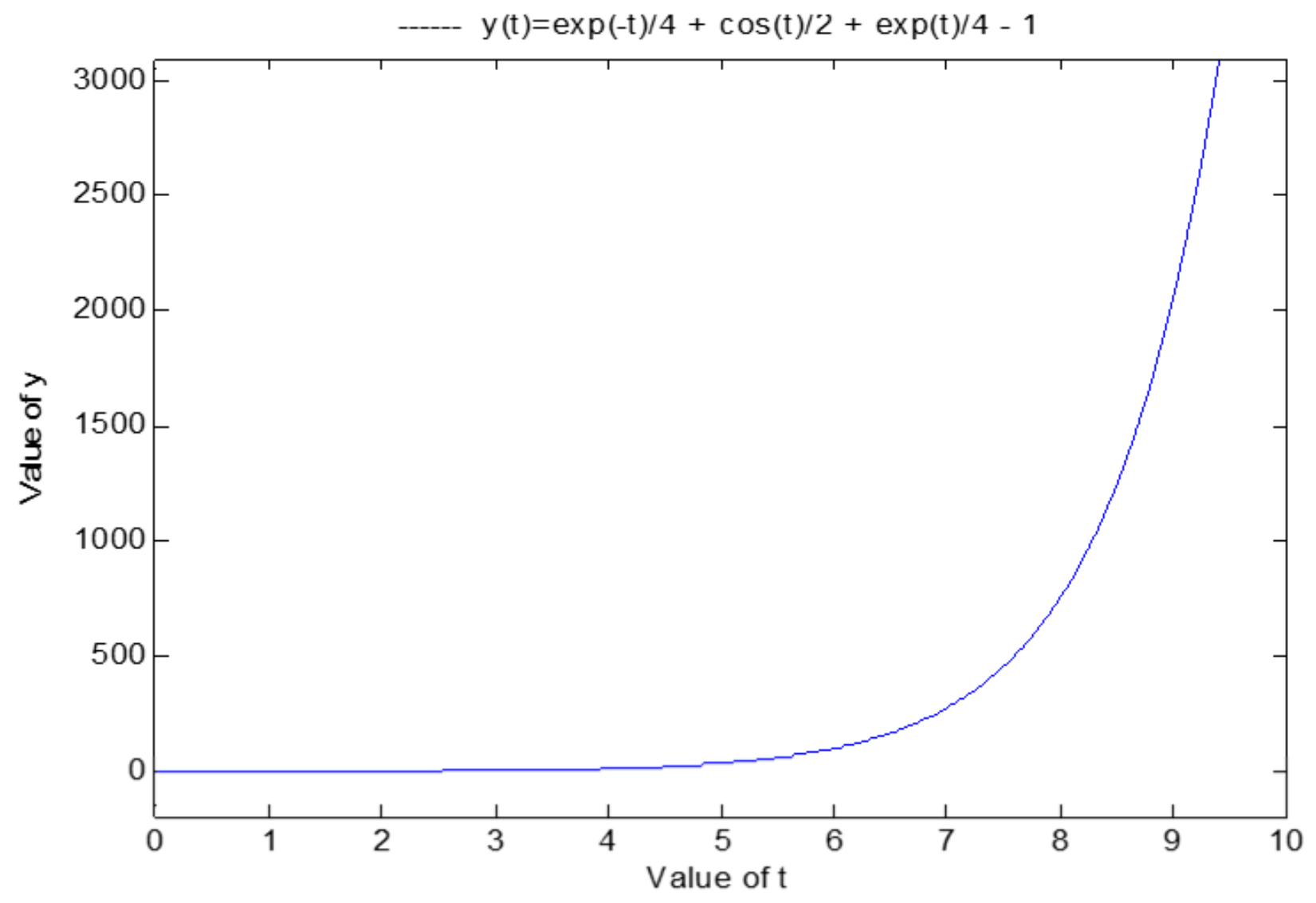

Fig 3.

2.4 Solve the differential equation $\frac{d^{3} y}{d t^{3}}+\frac{d y}{d t}=2, \quad y(0)=3, y^{\prime}(0)=1, y^{\prime \prime}(0)=-2$

Solution: Let $y^{\prime \prime \prime}(t)+y^{\prime}(t)=2, y(0)=3, y^{\prime}(0)=1, y^{\prime \prime}(0)=-2(2.4 .1)$ 
Now by taking the Elzaki transform to (2.4.1), we have

$$
E\left\{y^{\prime \prime \prime}(t)\right\}+E\left\{y^{\prime}(t)\right\}=2 E\{1\}
$$

Using the derivatives of transform, we have

$$
\frac{1}{v^{3}} E\{y(t)\}-\frac{1}{v} y(0)-y^{\prime}(0)-v y^{\prime \prime}(0)+\frac{1}{v} E\{y(t)\}-v y(0)=2 v^{2}
$$

Substituting the values given in conditions, we get

$$
\left(\frac{1}{v^{3}}+\frac{1}{v}\right) E\{y(t)\}-\frac{3}{v}-1+2 v-3 v=2 v^{2}
$$

Further it can be written as $\left(\frac{1+v^{2}}{v^{3}}\right) E\{y(t)\}=2 v^{2}+v+1+\frac{3}{v}$.

This implies

$$
\begin{aligned}
E\{y(t)\} & =\frac{2 v^{5}+v^{4}+v^{3}+3 v^{2}}{1+v^{2}} \\
& =2 v^{3}+v^{2}+\frac{2 v^{2}-v^{3}}{1+v^{2}}
\end{aligned}
$$

Taking inverse Elzaki transform of both sides (2.4.2), we get

$$
y(t)=2 E^{-1}\left\{v^{3}\right\}+E^{-1}\left\{v^{2}\right\}+2 E^{-1}\left\{\frac{v^{2}}{1+v^{2}}\right\}-E^{-1}\left\{\frac{v^{3}}{1+v^{2}}\right\}
$$

After simplification $y(t)=2 t+1+2 \cos t-\sin t$ is the required solution.

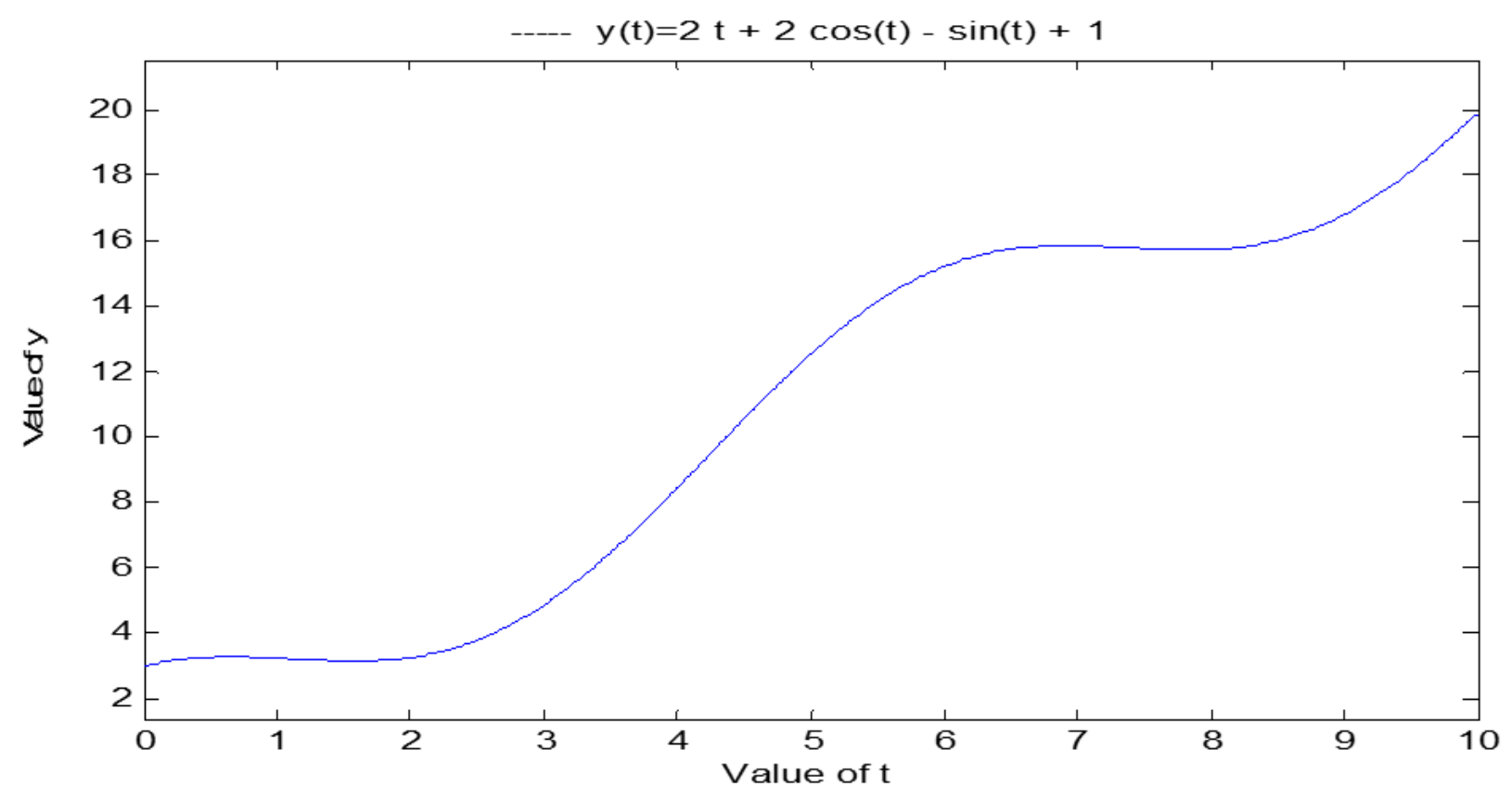

Fig 4. 


\section{Applications to Mechanics}

Here in this section we discuss solutions of some mechanics problems by using Elzaki transform technique.

3.1. Example : A particle with mass of 2 grams, which moves on $X$-axis and gets attracted towards the origin with a force $8 \mathrm{X}$. If $\mathrm{Q}$ is initially at rest at $\mathrm{X}=10$ then find its position at any time with an assumptions (i) No other external force acts on it (ii) A damping force equal to 8 times of the instantaneous velocity acts.

Solution: (i) From Newton's law, the equation of motion of the particle is $2 \frac{d^{2} X}{d t^{2}}=-8 X$ rewriting this as $\frac{d^{2} X}{d t^{2}}+4 X=0(3.1 .1)$, with initial conditions $X(0)=10$ and $X^{\prime}(0)=0$.

Now applying Elzaki transform to (3.1.1), we have $E\left\{\frac{d^{2} X}{d t^{2}}\right\}+4 E\{X\}=0$.

Using the derivatives of Elzaki transform, then

$$
\frac{1}{v^{2}} E\{X(t)\}-X(0)-v X^{\prime}(0)+4 E\{X(t)\}=0
$$

From the values given in conditions $\left(\frac{1}{v^{2}}+4\right) E\{X(t)\}-10-0=0$

$$
=\quad E\{X(t)\}=\frac{10 v^{2}}{1+4 v^{2}}
$$

Taking inverse transform either sides of (3.1.2), we get $X(t)=10 E^{-1}\left(\frac{v^{2}}{1+4 v^{2}}\right)$, Further gives the solution as $X(t)=10 \cos 2 t$.

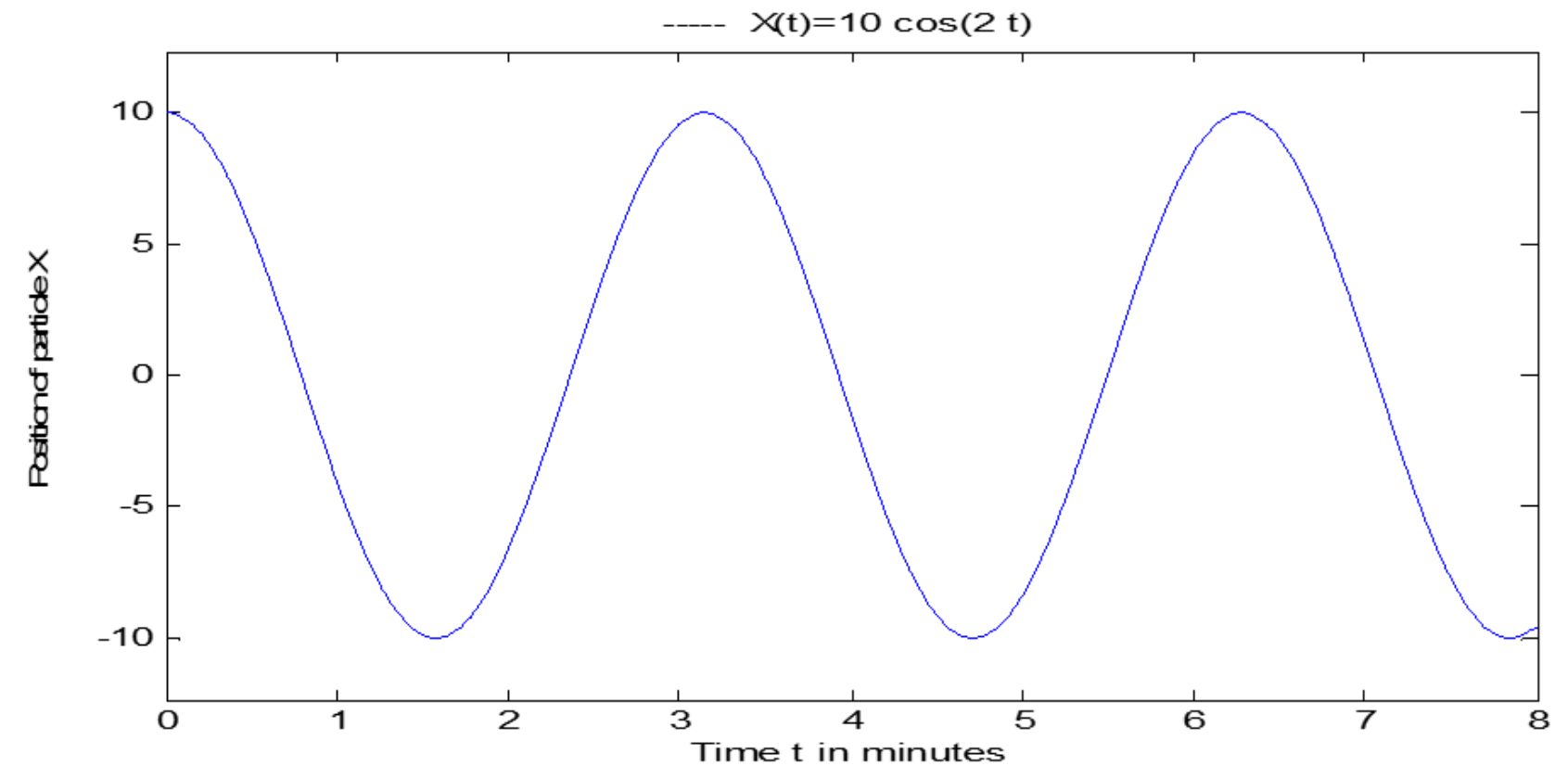

Fig 5.

(ii) In this case the equation of motion of a particle is $2 \frac{d^{2} X}{d t^{2}}=-8 X-8 \frac{d X}{d t}$. It can be written as $\frac{d^{2} X}{d t^{2}}+4 \frac{d X}{d t}+4 X=0(3.1 .3)$, with the initial conditions $X(0)=10$ and $X^{\prime}(0)=0$.

Now by taking the Elzaki transform of both sides of (3.1.3), we have $E\left\{\frac{d^{2} X}{d t^{2}}\right\}+4 E\left\{\frac{d X}{d t}\right\}+4 E\{X\}=0$. Using the derivatives of Elzaki transform, we get

$$
\frac{1}{v^{2}} E\{X(t)\}-X(0)-v X^{\prime}(0)+4\left[\frac{1}{v} E\{X(t)\}-v X(0)\right]+4 E\{X(t)\}=0
$$

Substituting the values of initial conditions, $\left(\frac{1}{v^{2}}+\frac{4}{v}+4\right) E(X(t)\}-10-0-40 v=0$, 
This implies $\left(\frac{1+4 v+4 v^{2}}{v^{2}}\right) E\{X(t)\}=10+40 v$.

$$
\text { Further } \begin{aligned}
E\{X(t)\} & =\frac{10 v^{2}}{(1+2 v)^{2}}+\frac{40 v^{3}}{(1+2 v)^{2}} \\
& =\frac{10 v^{2}}{1+2 v}-\frac{20 v^{3}}{(1+2 v)^{2}}+\frac{40 v^{3}}{(1+2 v)^{2}} \\
& =\frac{10 v^{2}}{1+2 v}+\frac{20 v^{3}}{(1+2 v)^{2}}
\end{aligned}
$$

Now by taking inverse Elzaki transform on either side of (3.1.4), we get the solution as $X(t)=10 e^{-2 t}+20 t e^{-2 t}$.

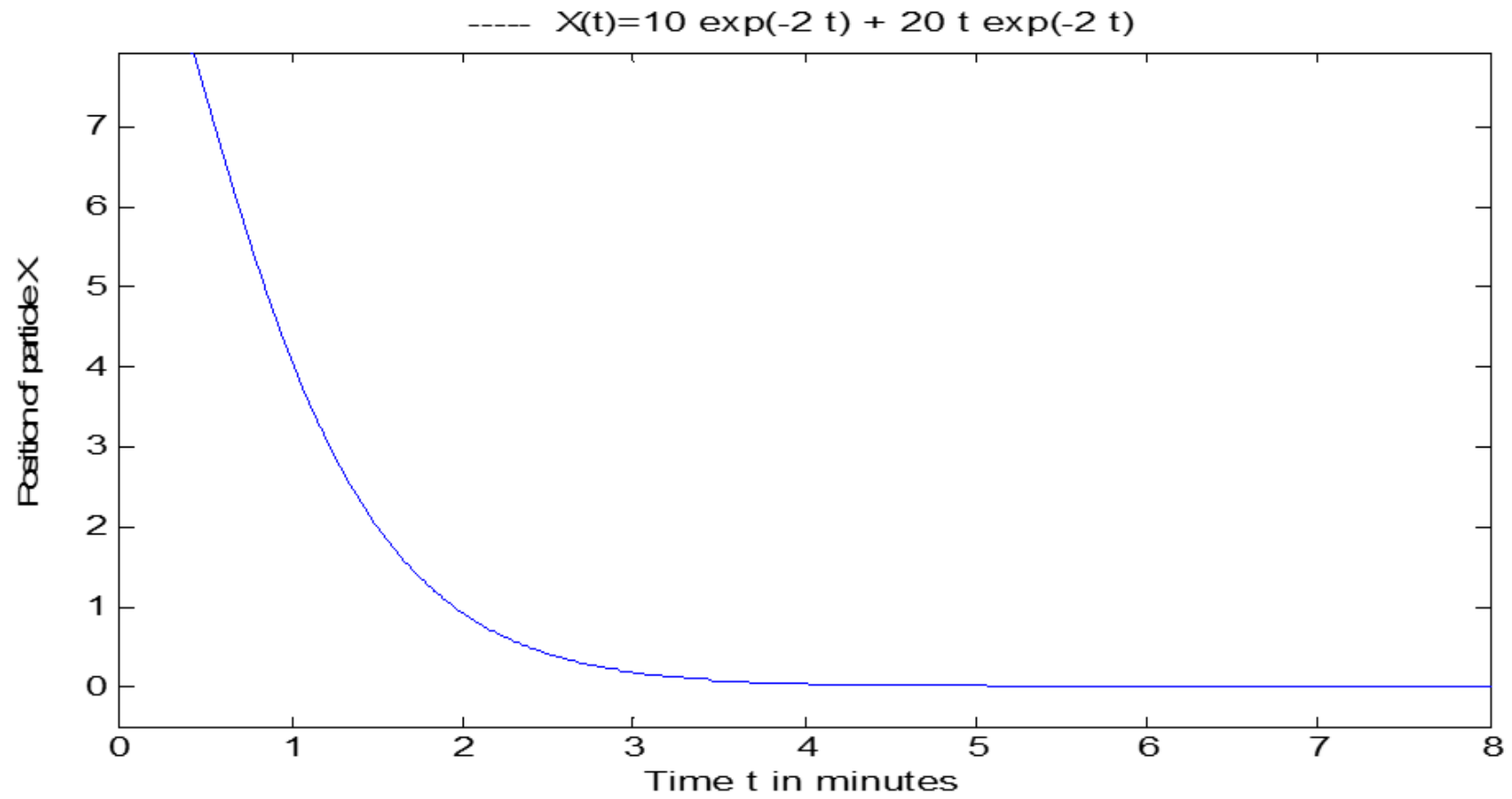

Fig 6.

3.2. Example : A body of mass $m$ moves along the $\mathrm{X}$-axis, it is under the influence of a force which is directly proportional to its instantaneous speed and in a direction opposite to the direction of motion. Assuming that at $\mathrm{t}=0$ the particle is located at $\mathrm{x}=a$ and moving to the right with a speed $V_{0}$, find the position where the mass comes to rest.

Solution:Here the equation of motion is $m \frac{d^{2} x}{d t^{2}}=-\mu \frac{d x}{d t} \quad$ (or) $m \frac{d^{2} x}{d t^{2}}+\mu \frac{d x}{d t}=0$ (3.2.1) with initial conditions $x(0)=a$ and $x^{\prime}(0)=V_{0}$.

Now by taking the Elzaki transform to (3.2.1), we have $m E\left\{\frac{d^{2} x}{d t^{2}}\right\}+\mu E\left\{\frac{d x}{d t}\right\}=0$. Using the derivatives of Elzaki transform, we have

$$
m\left[\frac{1}{v^{2}} E\{x(t)\}-x(0)-v x^{\prime}(0)\right]+\mu\left[\frac{1}{v} E\{x(t)-v x(0)]=0\right.
$$

Substituting the values given in conditions, we have $\left(\frac{m}{v^{2}}+\frac{\mu}{v}\right) E(x(t)\}-m a-m v V_{0}-\mu a v=0$ 
This can also be written as $\left(\frac{m+\mu v}{v^{2}}\right) E\{x(t)\}=m a+v\left(m V_{0}+\mu a\right)$.

$$
\begin{aligned}
=\quad E\{x(t)\} & =m a \frac{v^{2}}{m+\mu v}+\left(m V_{0}+\mu a\right) \frac{v^{3}}{m+\mu v} \\
& =a \frac{v^{2}}{1+\frac{\mu}{m} v}+\left(\frac{m V_{0}+\mu a}{m}\right) \frac{v^{3}}{1+\frac{\mu}{m} v} \\
& =a \frac{v^{2}}{1+\frac{\mu}{m} v}+\left(\frac{m V_{0}+\mu a}{m}\right)\left[\frac{m}{\mu} v^{2}-\frac{m}{\mu} \frac{v^{2}}{1+\frac{\mu}{m} v}\right] \\
& =\left(\frac{m V_{0}}{\mu}+a\right) v^{2}+\left(a-\frac{m V_{0}+\mu a}{\mu}\right) \frac{v^{2}}{1+\frac{\mu}{m} v} \\
& =\left(\frac{m V_{0}}{\mu}+a\right) v^{2}+-\frac{m V_{0}}{\mu} \frac{v^{2}}{1+\frac{\mu}{m} v}
\end{aligned}
$$

Now taking inverse Elzaki transform of both sides of (3.2.2), we get

$$
x(t)=\left(\frac{m V_{0}}{\mu}+a\right) E^{-1}\left\{v^{2}\right\}+-\frac{m V_{0}}{\mu} E^{-1}\left\{\frac{v^{2}}{1+\frac{\mu}{m} v}\right\}
$$

After simplification, the solution of the given differential equation is

$$
x(t)=\left(\frac{m V_{0}}{\mu}+a\right)-\frac{m V_{0}}{\mu} e^{-\frac{\mu}{m} t}
$$

Now if $\frac{d x}{d t}=V_{0} e^{-\frac{\mu}{m} t}=0$ then from (3.2.3), $x(t)=\frac{m V_{0}}{\mu}+a$.

Hence the mass $m$ comes to rest at a distance $\frac{m V_{0}}{\mu}+a$ from the center $\mathrm{O}$.

3.3. Example : A spring hangs vertically. A weight of $10 \mathrm{lb}$. is attached and the spring stretches 2 inches. The weight is replaced with a $60 \mathrm{lb}$. weight and allowed to come to rest in equilibrium. It is then pulled down 6 inches and released with velocity zero. Find the formula for the resulting motion.

Solution: From Newton's second law of motion, we have $m \frac{d^{2} s}{d t^{2}}=-k s$ (3.3.1) where $m$ is the mass, and $-k s$ is the force exerted by the spring. The force constant $k$ can be defined as

$$
\begin{gathered}
k=[(\text { force applied }) /(\text { distance stretched })] \\
\text { Thus, } k=[(10 \mathrm{lb}) /(2 \text { inches })]=[(10 \mathrm{lb}) /\{(1 / 6 \mathrm{ft})]=60 \mathrm{lb} / \mathrm{ft} .
\end{gathered}
$$

The mass of the $60 \mathrm{lb}$. and weight is $=\left(\frac{w}{g}\right)=\left[\frac{60 l b}{g}\right]$, where $g=$ the acceleration due to gravity.

Substituting these values in (3.3.1), we get $\left(\frac{60}{g}\right)\left(\frac{d^{2} s}{d t^{2}}\right)=-60 s$.

This can be written as $\frac{d^{2} s}{d t^{2}}+g s=0$ (3.3.2) with the initial conditions are

$$
s(0)=-6 \text { inches }=-\frac{1}{2} f t ; v(0)=s^{\prime}(0)=0
$$

Taking the Elzaki transform of both sides of (3.3.2), we have

$$
E\left\{\frac{d^{2} s}{d t^{2}}\right\}+g E\{s\}=0
$$

this implies $\frac{1}{v^{2}} E\{s(t)\}-s(0)-v s^{\prime}(0)+g E\{s\}=0$. 
Substituting the initial conditions, we have

$$
\begin{aligned}
& \left(\frac{1}{v^{2}}+g\right) E\{s(t)\}+\frac{1}{2}-0=0 \\
\Rightarrow & E\{s(t)\}=-\frac{1}{2} \frac{v^{2}}{1+g v^{2}}
\end{aligned}
$$

Now applying inverse Elzaki transform of both sides of (3.3.3), we get $s(t)=-\frac{1}{2} E^{-1}\left\{\frac{v^{2}}{1+g v^{2}}\right\}=-\frac{1}{2} \cos (\sqrt{g} t)($ or $)-$ $\frac{1}{2} \cos h(\sqrt{-g} t) f t$, is the solution.

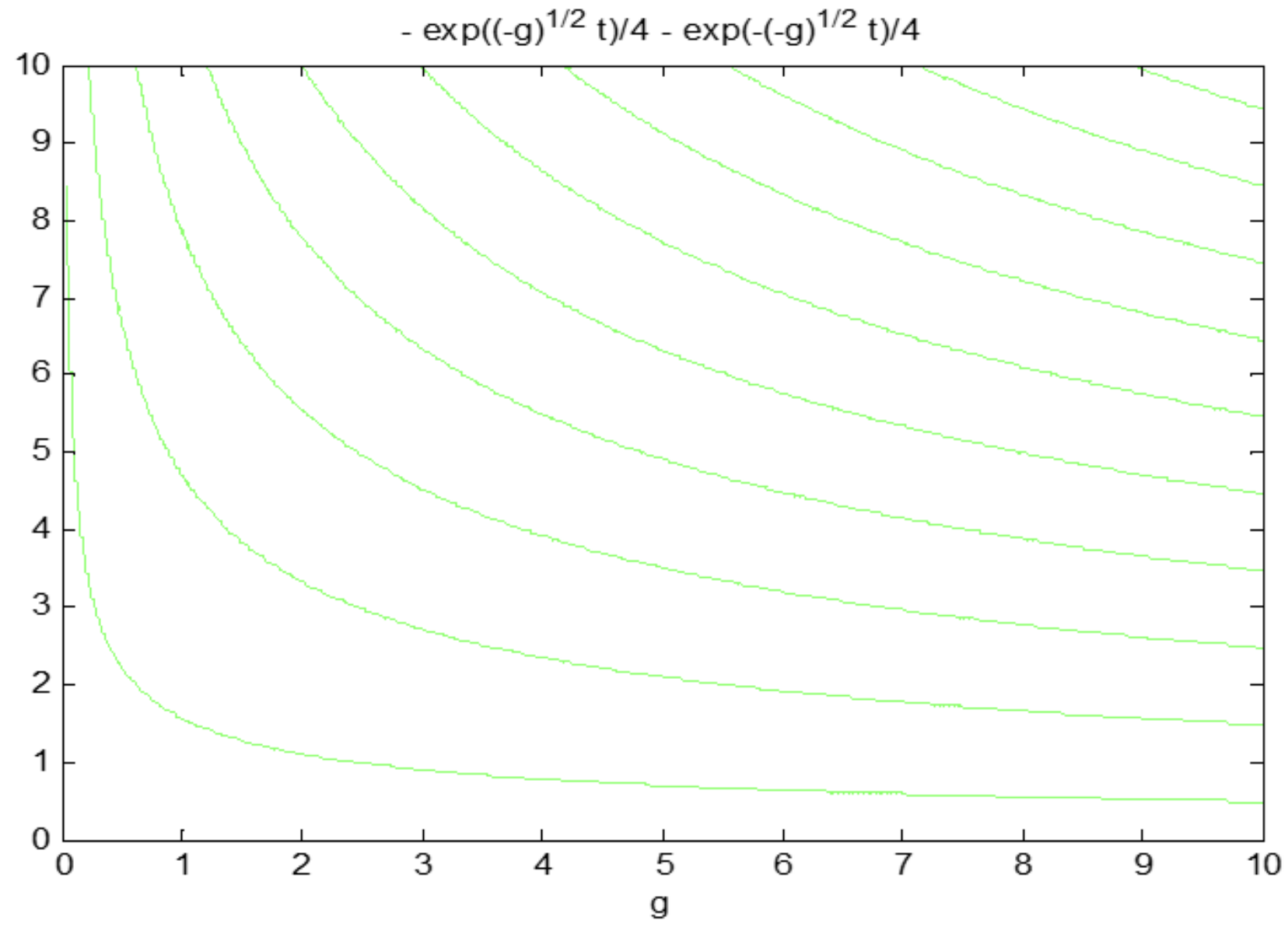

Fig 7.

3.4. Example : A 10-kilogram mass is attached to a spring which is thereby stretched 0.7 meters from its natural length. The mass is started in motion from the equilibrium position with an initial velocity of $1 \mathrm{~meter} / \mathrm{sec}$ in the upward direction. Find the resulting motion if the force due to air resistance is $-90 \frac{d x}{d t}$ newtons.

Solution: The motion is damped (air resistance) and free (no external force). From Newton's Second law, $m \frac{d^{2} x}{d t^{2}}=-90 \frac{d x}{d t}-k x$ (3.4.1), where $m=$ the mass $(10 \mathrm{~kg})$, and $k$ is the spring constant.

Since $k=[\{(9.8)(10)\} / 0.7]=140$ Newton's/meter. (Note that a mass of $10 \mathrm{~kg}$ exerts a force or weight of $(9.8) *(10)=98$ Newton's).

Substitute these values in (3.4.1),

$$
\text { we have } 10 \frac{d^{2} x}{d t^{2}}=-90 \frac{d x}{d t}-140 x \text { (or) } \frac{d^{2} x}{d t^{2}}+9 \frac{d x}{d t}+14 x=0
$$


with the initial conditionals $x(0)=0$ and $x^{\prime}(0)=-1$ (the initial velocity is in the negative $\mathrm{x}$-direction). Now taking the Elzaki transform to (3.4.2), we have

$$
\begin{gathered}
E\left\{\frac{d^{2} x}{d t^{2}}\right\}+9 E\left\{\frac{d x}{d t}\right\}+14 E\{x\}=0 \\
=>\frac{1}{v^{2}} E\{x(t)\}-x(0)-v x^{\prime}(0)+9\left[\frac{1}{v} E\{x(t)\}-v x(0)\right]+14 E\{x(t)\}=0
\end{gathered}
$$

Substituting the values of conditions, we get $\left(\frac{1}{v^{2}}+\frac{9}{v}+14\right) E\{x(t)\}-0+v-0=0$

$$
=>\left(\frac{1+9 v+14 v^{2}}{v^{2}}\right) E\{x(t)\}=-v
$$

Further it can be expressed as $E\{x(t)\}=\frac{-v^{3}}{(1+2 v)(1+7 v)}$

$$
=-\frac{1}{5} \frac{v^{2}}{1+2 v}+\frac{1}{5} \frac{v^{2}}{1+7 v}
$$

Applying inverse transform to (3.4.3), we get $x(t)=-\frac{1}{5} e^{-2 t}+\frac{1}{5} e^{-7 t}$, is the required solution.

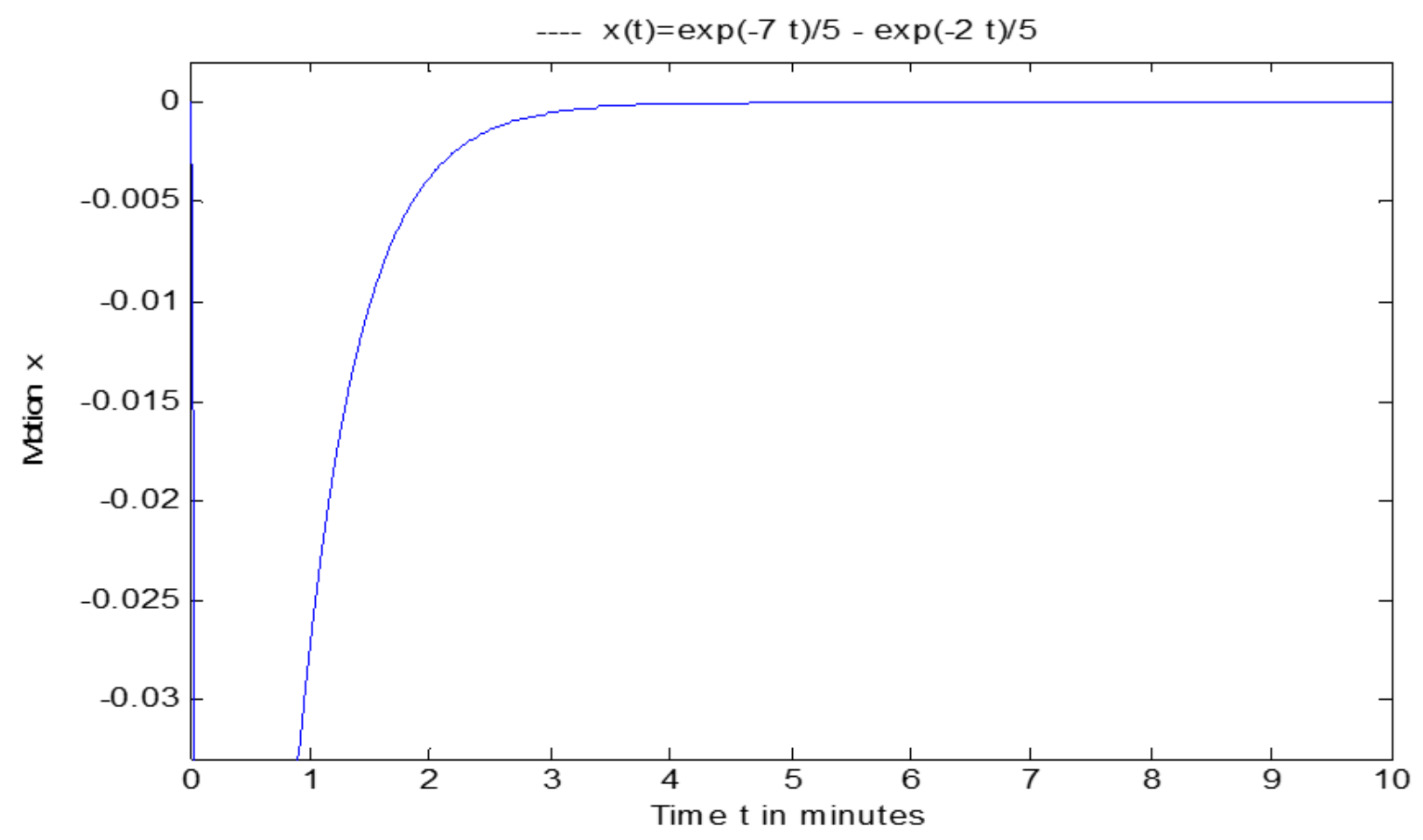

Fig 8.

3.5. Example : A mass of $1 / 4^{\text {th }}$ slug is attached to a spring of force constant $\mathrm{k}=1 \mathrm{lb} / \mathrm{ft}$. The mass is set in motion by initially displacing it $2 \mathrm{ft}$. in the downward direction, and giving it an initial velocity of $2 \mathrm{ft}$./sec. in the upward direction. Find the subsequent motion of the mass if the force due to air resistance is $-1(\mathrm{dx} / \mathrm{dt}) \mathrm{lb}$.

Solution: From Newton's second law, $m \frac{d^{2} x}{d t^{2}}=-a \frac{d x}{d t}-k x$ (3.5.1), where $-a \frac{d x}{d t}$ is the force of air resistance and $-k x$ is the spring force. Substituting the values in (3.5.1),

$$
\left.\frac{1}{4} \frac{d^{2} x}{d t^{2}}=-1 \frac{d x}{d t}-1 . x \quad \text { (or }\right) \frac{d^{2} x}{d t^{2}}+4 \frac{d x}{d t}+4 x=0
$$

with the initial conditions $x(0)=2$ and $x^{\prime}(0)=-2$. 
Taking the Elzaki transform to (3.5.2), we get $E\left\{\frac{d^{2} x}{d t^{2}}\right\}+4 E\left\{\frac{d x}{d t}\right\}+4 E\{x\}=0$. Using the derivative of Elzaki transform

$$
\frac{1}{v^{2}} E\{x(t)\}-x(0)-v x^{\prime}(0)+4\left[\frac{1}{v} E\{x(t)\}-v x(0)\right]+4 E\{x(t)\}=0
$$

substituting the values of conditions, $\left(\frac{1}{v^{2}}+\frac{4}{v}+4\right) E\{x(t)\}-2+2 v-8 v=0$.

Further it can be rewritten as $\left(\frac{1+4 v+4 v^{2}}{v^{2}}\right) E\{x(t)\}=2+6 v$.

$$
\begin{aligned}
\Rightarrow \quad E\{x(t)\} & =\frac{2 v^{2}}{(1+2 v)^{2}}+\frac{6 v^{3}}{(1+2 v)^{2}} \\
& =\frac{2 v^{2}}{1+2 v}-\frac{4 v^{3}}{(1+2 v)^{2}}+\frac{6 v^{3}}{(1+2 v)^{2}} \\
& =\frac{2 v^{2}}{1+2 v}+\frac{2 v^{3}}{(1+2 v)^{2}}
\end{aligned}
$$

Now by taking inverse Elzaki transform to above (3.5.3), we get

$$
\begin{aligned}
& x(t)=2 E^{-1}\left\{\frac{v^{2}}{1+2 v}\right\}+2 E^{-1}\left\{\frac{v^{3}}{(1+2 v)^{2}}\right\} \\
& \therefore x(t)=2 e^{-2 t}+2 t e^{-2 t}=2(1+t) e^{-2 t}
\end{aligned}
$$

is the solution.

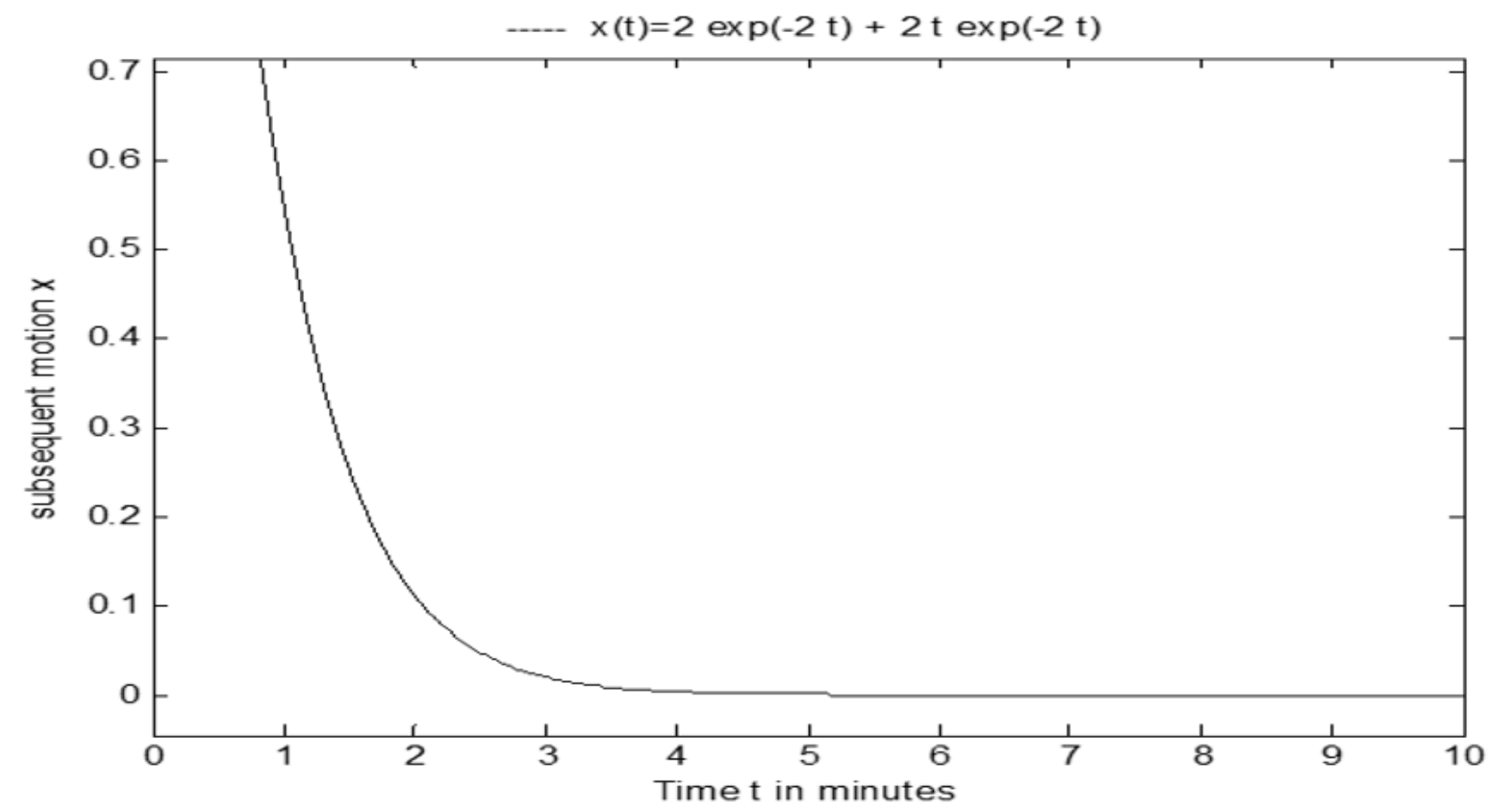

Fig 9.

3.6. Example: Find the solution of the suspended spring if the vibration is free and undamped.

Sol: By a suspended spring we mean a spring hanging vertically with top end fixed and bottom end handling a mass $m$. Initially, the spring and mass are in equilibrium position. Then at $t=0$, the spring is stretched by moving the mass at $x_{0}$, some positive distance below the equilibrium position. It is then released from rest. 
Thus, the initial conditions are

$$
x(0)=x_{0} \text { and } v(0)=x^{\prime}(0)=0
$$

where $x(t)$ is the position of the mass at $t$, and $v(t)=\frac{d x(t)}{d t}$ is its velocity.

If the vibration is free, we mean there is no external force, $F(t)$.

If the vibration is undamped, we mean there is no air or medium resistance force. Thus, the only force acting on our system is the force of the spring which by Hooke's law is $k x$.

By Newton's second law, our differential equation is

$$
m \frac{d^{2} x}{d t^{2}}=-k x \quad(\text { or }) \quad \frac{d^{2} x}{d t^{2}}+\frac{k}{m} x=0
$$

Now taking the Elzaki transform to (3.6.2), we have $E\left\{\frac{d^{2} x}{d t^{2}}\right\}+\frac{k}{m} E\{x\}=0$, using the derivatives of Elzaki transform, then

$$
\frac{1}{v^{2}} E\{x(t)\}-x(0)-v x^{\prime}(0)+\frac{k}{m} E\{x(t)\}=0
$$

Substituting the condition (3.6.1), then it became as $\left(\frac{1}{v^{2}}+\frac{k}{m}\right) E\{x(t)\}-x_{0}-0=0$ further it can be as

$$
\left(\frac{m+k v^{2}}{m v^{2}}\right) E\{x(t)\}=x_{0} \quad \text { or } E\{x(t)\}=\frac{x_{0} m v^{2}}{m+k v^{2}}
$$

Now applying inverse Elzaki transform rewritten to (3.6.3), we get

$$
x(t)=x_{0} E^{-1}\left\{\frac{v^{2}}{1+\frac{k}{m} v^{2}}\right\} \text {, implies } x(t)=x_{0} \cos \left(t \sqrt{\frac{k}{m}}\right)
$$

$x_{0}$ is called the amplitude of the motion, and $\sqrt{\frac{k}{m}}$ is the circular frequency. The natural frequency is defined as $f=\frac{1}{2 \pi} \sqrt{\frac{k}{m}}$. And the period is defined as $T=\frac{1}{f}=2 \pi \sqrt{\frac{m}{k}}$.

\section{Conclusion}

This new kind of Elzaki Transform technique is useful in finding the analytical solutions of differential equations occurred in the discipline of Engineering Mechanics.

\section{References}

1) Elzaki MT, Elzaki MS. The new integral transform Elzaki transform. Global Journal of pure and Applied Mathematics. 2011;p. 57-64. Available from: a.https://www.researchgate.net/publication/289123241_The_new_integral_transform_Elzaki_transform.

2) Tarig E, Salih M, Ezaki. On the Elzaki Transform and Systems of Ordinary Differential Equations. Global Journal of pure and Applied Mathematics. 2011;7(1):113-119. Available from: a.https://www.researchgate.net/publication/228533772_On_the_ELzaki_Transform_and_Systems_of_Ordinary_ Differential_Equations.

3) Varma D, Alam A. Analysis of Simultaneous Differential equations by Elzaki transform Approach. Science, Technology and Development. 2020;9(1):364367. Available from: https://www.researchgate.net/publication/338884992_ANALYSIS_OF_SIMULTANEOUS_DIFFERENTIAL_EQUATIONS_BY_ ELZAKI_TRANSFORM_APPROACH.

4) Sharjeel S, Barakzai MAK. Some New Applications of Elzaki Transform for Solution of Linear Volterra Type Integral Equations. Journal of Applied Mathematics and Physics. 2019;07(08):1877-1892. Available from: https://dx.doi.org/10.4236/jamp.2019.78129.

5) Agarwal S, Chauhan R, Sharma N. International Journal of in Advent Technology. 2018;6(12):3687-3692. Available from: a.https://www.researchgate.net/ publication/331154497_Application_of_Elzaki_Transform_for_Solving_Linear_Volterra_Integral_Equations_of_First_Kind.

6) Mahgob MMA, Elzaki TM. Solution of partial integro-differential equations by Elzaki transform method. Applied Mathematical Sciences. 2015;9(6):295303. Available from: https://dx.doi.org/10.12988/ams.2015.411984. 